\title{
17-ß3-estradiol affects nuclear image properties in MCF-10F human breast epithelial cells with tumorigenesis
}

\author{
MARIA LUIZA S. MELLO ${ }^{1}$, PATRICIA RUSSO ${ }^{2}$, JOSE RUSSO $^{2}$ and BENEDICTO C. VIDAL ${ }^{1}$ \\ ${ }^{1}$ Department of Cell Biology, Institute of Biology, UNICAMP, 13083-863 Campinas (SP), Brazil; ${ }^{2}$ Breast Cancer \\ Research Laboratory, Fox Chase Cancer Center, 333 Cottman Avenue, Philadelphia, PA 19111, USA
}

Received June 22, 2007; Accepted August 10, 2007

\begin{abstract}
Treatment of the human breast epithelial cells MCF-10F with 17-ß-estradiol (E2) induces transformation and tumorigenesis. E2-transformed MCF-10F cells are known to exhibit progressive loss of ductulogenesis, and invasive and tumorigenic phenotypes. Although DNA amounts and chromatin supraorganization change in E2-transformed MCF cells, no comparative study has yet been undertaken in the resulting cells selected for aggressive invasiveness (C5) and tumor generation in a heterologous host. The aim of this study was thus to determine whether changes in Feulgen-DNA content and chromatin supraorganization are involved during E2-induced transformation and tumorigenesis of the MCF-10F cells. Image analysis was performed for nontransformed and E2-transformed MCF cells, highly invasive cells (C5), and for cell lines (C5-A6-T6 and C5-A8-T8) derived from tumors generated by injection of C5 cells in SCID mice. A decrease in Feulgen-DNA amounts and nuclear sizes induced by E2 treatment was accented with selection of the highly invasive tumorigenesis potential. However, in the tumor-derived cells a high variability in cellular phenotypes resulted inclusively in near-polyploidy. Significant changes in textural parameters, including nuclear entropy, indicated chromatin structural remodeling with advancing tumorigenesis. An increased variability in the degree of chromatin packing states in the E2-transformed MCF cells is followed by reduction in chromatin condensation and in contrast between condensed and noncondensed chromatin in the highly invasive C5 cells and tumor-derived cell lines. Studies on epigenetic mechanisms involving DNA methylation and/or the histone code would contribute to a better interpretation of the chromatin supraorganization changes reported herein.
\end{abstract}

Correspondence to: Dr Maria Luiza S. Mello, Department of Cell Biology, Institute of Biology, UNICAMP, 13083-863 Campinas (SP), Brazil

E-mail:mlsmello@unicamp.br

Key words: human breast epithelial cells, 17-ß-estradiol, tumorderived cells, chromatin packing states, image analysis

\section{Introduction}

Treatment of MCF-10F estrogen receptor $\alpha(\mathrm{ER}-\alpha)$-negative immortalized human breast epithelial cells with 17- $\beta$-estradiol (E2) results in anchorage-independent growth, colony formation in agar-methocel, increase in cell proliferation and in invasive capability in Matrigel (1), loss of heterozygosity in chromosomes 13 and $17(2,3)$, and loss of the 9p11-13 locus (4). The 9p11-13 locus is known to contain a putative tumor suppressor gene (5). Treatment of the MCF-10F cells with E2 twice a week for two weeks also results in changes in DNA amounts, nuclear sizes and chromatin higher order packing states (supraorganization) (6). Many of these changes are similar to the effects caused by the carcinogen benzo[a]pyrene (BP) which are indicative of neoplastic transformation in vitro $(2,3,6,7)$.

The above-mentioned findings suggest that transformation by E2 may occur by a mechanism independent of the presence of ER- $\alpha$, since the expression of the cell phenotypes indicative of neoplastic transformation as well as the changes in Feulgen-DNA amounts and nucleus image properties in E2treated MCF-10F cells are not abrogated when these cells are treated simultaneously with E2 and the estrogen antagonist, ICI182,780 (6,8).

Selection of the most highly invasive E2-transformed MCF-10F cells in Matrigel chambers has generated transformed cells with phenotypic/genotypic variations correlated with their tumorigenic potential in SCID mice (4). Only invasive cells with a 4p15.3-16 deletion were tumorigenic. The generated tumors (adenocarcinomas) exhibited genomic alterations similar to those described in primary breast cancer, as determined by comparative genomic hybridization (4). Tumors and tumor-derived cell lines exhibited loss of chromosome 4, deletions in chromosomes 3p12.3-13, 8p11.1-21, 9p21-qter, and 18q, and gains in 1p, and 5q15-qter (4). The 9p21-qter region includes the p16 and p15 genes, their lack thus possibly contributing to the progression of the invasive to the tumorigenic states in the natural progression of the disease (4). The chromosome arm 18q, a region frequently lost in breast cancer (9-14) may involve one or more tumor-suppressor genes (4). Amplification of $1 \mathrm{p}$ has been reported in breast cancer cell lines (15) and in primary breast cancer (13). 
In early E2-transformed MCF-10F cells certain losses of DNA, changes in nuclear sizes, and chromatin remodeling have been assessed by image analysis procedures (6). One of the most heterogeneous distributions of chromatin packing states ever observed, such that an increase in chromatin condensation in certain sectorial nuclear domains coexisted with a decrease in condensation in less packed zones was demonstrated by high nuclear entropy and absorbance variability per nucleus in the Feulgen-stained E2-transformed cells (6). Changes in nuclear image properties, including chromatin supraorganization remodeling, and decreased Feulgen-DNA content, whether similar to those present in the E2-treated MCF-10F cells in vitro, have so far not been studied in the highly invasive and resulting tumor-derived cells. This investigation would be required for demonstrating that the previously reported changes in these parameters in early E2 transformed MCF-10F cells could be associated with a complete transformation in a heterologous host.

Nuclear image properties and Feulgen-DNA values were thus evaluated in highly invasive tumorigenic E2-transformed MCF-10F cells and tumor-derived cell lines studied by Russo and co-workers (4) as regards other cell parameters (selection of cells by Matrigel invasion assay, colony formation in agarmethocel, ductulogenic, invasion and tumorigenic assays, verification of cell lineage, screening for E2-induced genetic changes, development of cell lines from tumors, and histopathological, immunocytochemical and DNA fingerprint analyses).

\section{Materials and methods}

Cells and treatments. The cells used consisted of the spontaneously immortalized human breast epithelial cell line, MCF-10F, E2-treated MCF-10F cells, the tumorigenic C5 cell line selected from the E2-treated MCF-10F cells, and C5-A6-T6 and C5-A8-T8 cells, obtained from tumors generated in SCID mice injected with C5 cells (4).

MCF-10F cells were cultured in DMEM:F-12 medium containing $1.05 \mathrm{mM}$ calcium, antibiotics, antimycotics, hormones, growth factors and equine serum as described previously (16). E2 cells consisted of MCF-10F cells in their $123 \mathrm{rd}$ passage, treated with $70 \mathrm{nM} 17-\beta$-estradiol as described previously (4). The choice of the E2 concentration was based on previous studies which evaluated colony efficiency in agar methocel, number of solid masses in collagen gel, invasiveness in the Matrigel invasion chamber $(2,4,8)$, and chromatin remodeling (6). E2 cells at passage 10 were used.

Cells expanded from the 10th passage of E2 cells were named C5; these cells developed poorly differentiated adenocarcinomas when injected in 9 out of 10 SCID mice (4). The tumoral cell lines derived from tumors induced in the SCID mice, C5-A6-T6 and C5-A8-T8, were used at passage three, the same passage for which fingerprint and tumorigenic assay analyses have been reported (4).

The cells used were cultured for $96 \mathrm{~h}$ (MCF-10F cells) and $48 \mathrm{~h}$ (the other cell types) at 70-80\% confluence on $9.4 \mathrm{~cm}^{2}$ plastic chamber slides (17), fixed in an absolute ethanolacetic acid mixture (3:1, v/v) for $1 \mathrm{~min}$, rinsed in $70 \%$ ethanol for $5 \mathrm{~min}$, and air dried. The preparations were then subjected to the Feulgen reaction $\left(4 \mathrm{M} \mathrm{HCl}\right.$ at $24^{\circ} \mathrm{C}, 75 \mathrm{~min}$ ), and mounted in Cargille oil (Cedar Grove, NJ, USA) $\left(\mathrm{n}_{\mathrm{D}}=1.54\right)$. Three slides were used for each experimental condition.

Video image analysis. Two hundred interphase nuclei chosen at random for each experimental condition were measured using Carl Zeiss/Kontron equipment and Kontron KS400 software (Oberkochen/Munich, Germany). The microscopic images were obtained with a Zeiss Axiophot 2 microscope equipped with a Neofluar 40/0.75 objective, optovar factor 2 , 0.90 condenser, and light of wavelength equal to $546 \mathrm{~nm}$, provided by a Schott interference filter. A $100-\mathrm{W}$ halogen illuminator, a voltage regulator for light intensity maintained constant at point 4 , filter wheels 1 and 2 rotated into position 100 (open position), and a luminous-filter diagram (transmitted light) at its maximal opening were used. These illumination conditions were maintained constant for all nuclei investigated. The images to be processed were fed from the microscope into a Pentium computer through a Sony CCD IRIS/RGB Hyper HAD color video camera. Two threshold values determined which gray value range of the image Input is retained or deleted in the image Output. Threshold values (gray values) named Low $(\mathrm{L})$ and High $(\mathrm{H})$ were determined by moving the borders in the gray value histogram such that nuclear images appeared well segmented from each other and from the background (18). Since 'green' was selected as the parameter 'color', the pixels inside the gray value range $(\mathrm{L}, \mathrm{H})$ were displayed in this color. In the present study, $\mathrm{L}$ and $\mathrm{H}$ threshold values were equal to 0 and 116-120, respectively. Under the operating conditions used, $1 \mu \mathrm{m}$ corresponded to 7.23 pixels. The minimum area possible to be measured with this apparatus corresponded to four pixels.

The software provided quantitative information on 1) geometric parameters such as nuclear total area $\left(\mu \mathrm{m}^{2}\right)$, nuclear absorbing area $\left(\mu \mathrm{m}^{2}\right)$, nuclear perimeter $(\mu \mathrm{m})$, and nuclear feret ratio (minimal feret/maximal feret, as an indication of the elliptical shape of the nuclear absorbing image), 2) densitometric parameters such as mean gray value per nucleus [subsequently converted into absorbances or optical density (OD)], and integrated optical density (IOD), and 3) textural parameters, such as standard deviation of the total densitometric values per nucleus or absorbance variability per nucleus (SDtd), and nuclear entropy (E). SDtd reflects the variability in the degree of chromatin packing state per Feulgen-stained image $(18,19)$. Entropy is considered the number of bits necessary to store the densitometric values per nucleus image or amount of gray value variability in a nucleus. Since it measures the complexity of an image (20), a high entropy value for Feulgen-stained nuclei represents a high contrast between condensed and noncondensed chromatin, whereas a low entropy value is an indicator of an image with fairly constant gray levels (homogeneous image) $(18,19,21)$.

For conversion of the mean gray values into absorbances, gray values of 0 and 255 corresponded to light transmittances of 0 and $100 \%$, respectively. IOD, in this case, Feulgen-DNA content, was equal to the absorbances multiplied by the nuclear absorbing area.

Statistical analysis. Calculations were done using Minitab12 ${ }^{\mathrm{TM}}$ software (State College, PA). Applied tests consisted of one-way analysis of variance for unstacked data and MannWhitney U test. 
Table I. Nuclear phenotypes: video image geometric parameters.

\begin{tabular}{|c|c|c|c|c|c|c|c|c|}
\hline \multirow[b]{2}{*}{ Cells } & \multicolumn{2}{|c|}{ Nuclear area $\left(\mu \mathrm{m}^{2}\right)$} & \multicolumn{2}{|c|}{ Nuclear absorbing area $\left(\mu \mathrm{m}^{2}\right)$} & \multicolumn{2}{|c|}{ Nuclear perimeter $(\mu \mathrm{m})$} & \multicolumn{2}{|c|}{ Feret ratio } \\
\hline & $X$ & $\mathrm{~S}$ & $\mathrm{X}$ & $\mathrm{S}$ & $\mathrm{X}$ & $\mathrm{S}$ & $\mathrm{X}$ & S \\
\hline MCF-10F (control) & 247.87 & 79.86 & 247.08 & 79.48 & 107.43 & 48.41 & 0.75 & 0.10 \\
\hline E2 & 188.03 & 72.57 & 187.71 & 72.01 & 79.38 & 32.89 & 0.75 & 0.10 \\
\hline $\mathrm{C} 5$ & 147.03 & 31.39 & 146.42 & 31.25 & 83.15 & 23.22 & 0.84 & 0.06 \\
\hline C5-A6-T6 & 160.17 & 56.97 & 158.54 & 53.88 & 100.90 & 74.22 & 0.81 & 0.08 \\
\hline C5-A8-T8 & 185.24 & 67.57 & 183.09 & 65.51 & 123.95 & 72.75 & 0.81 & 0.07 \\
\hline
\end{tabular}

$\mathrm{n}=200$; E2, MCF-10F cells treated with 17-ß-estradiol; C5, cells expanded from E2; C5-A6-T6 and C5-A8-T8, tumor cells; S, standard deviation; $\mathrm{X}$, arithmetic mean.

Table II. Nuclear phenotypes: densitometric and textural parameters.

\begin{tabular}{|c|c|c|c|c|c|c|c|c|}
\hline \multirow[b]{2}{*}{ Cells } & \multicolumn{2}{|c|}{ Absorbances (OD) } & \multicolumn{2}{|c|}{ Feulgen-DNA amounts (IOD) } & \multicolumn{2}{|c|}{ SDtd } & \multicolumn{2}{|c|}{ Entropy } \\
\hline & $\mathrm{X}$ & $\mathrm{S}$ & $\mathrm{X}$ & $\mathrm{S}$ & $X$ & $\mathrm{~S}$ & $\mathrm{X}$ & $\mathrm{S}$ \\
\hline MCF-10F (control) & 0.46 & 0.03 & 113.54 & 36.72 & 8.32 & 2.12 & 4.99 & 0.35 \\
\hline E2 & 0.44 & 0.04 & 82.58 & 28.82 & 12.04 & 3.02 & 5.50 & 0.35 \\
\hline $\mathrm{C} 5$ & 0.40 & 0.03 & 58.66 & 13.11 & 8.32 & 2.40 & 4.96 & 0.38 \\
\hline C5-A6-T6 & 0.38 & 0.02 & 60.23 & 19.50 & 8.20 & 2.02 & 4.94 & 0.36 \\
\hline C5-A8-T8 & 0.36 & 0.02 & 65.63 & 22.86 & 7.69 & 1.85 & 4.82 & 0.34 \\
\hline
\end{tabular}

n=200; E2, MCF-10F cells treated with 17-ß-estradiol; C5, cells expanded from E2; C5-A6-T6 and C5-A8-T8, tumor cells; S, standard deviation; SDtd, standard deviation of total densitometric values per nucleus; $\mathrm{X}$, arithmetic mean.

\section{Results}

Treatment with E2 decreased the total and Feulgen absorbing nuclear areas, the nuclear perimeter, the absorbances and the Feulgen-DNA values (IOD) of the MCF-10F cells, but increased their SDtd and entropy values. The nuclear feret ratio was not affected (Tables I-III).

In expanded E2 cells (C5 cells) all the parameters, with the exception of the nuclear perimeter and feret ratio, decreased in comparison to the E2 cells. The nuclear perimeter and feret ratio of the C5 cells were bigger than those of the E2 cells (Tables I-III).

Different values for the parameters studied herein, with the exception of those regarding the feret ratio, were obtained for the C5-A6-T6 and C5-A8-T8 tumor cells compared to each other (Table III). Larger nuclear total and absorbing areas, perimeters and Feulgen-DNA values were demonstrated for the C5-A8-T8 tumor cells, whereas larger absorbances, SDtd and entropy values were detected in the C5-A6-T6 tumor cell values (Tables I-III).

In comparison to the $\mathrm{C} 5$ cells, larger total and absorbing nuclear areas, and nuclear perimeters, but smaller feret ratio and absorbances were found in the tumor cells. C5 and C5-A6-T6 cells did not differ from each other in terms of Feulgen-DNA, SDtd and entropy values; C5-A8-T8 tumor cells presented larger Feulgen-DNA values but smaller SDtd and entropy values in comparison to the C5 cells (Tables II and III).

In comparison to the E2 cells, the two tumor cell lines presented larger nuclear perimeters and feret ratio, but smaller absorbances, Feulgen-DNA, SDtd and entropy values. In terms of total and absorbing nuclear areas, C5-A8-T8 and E2 cells did not differ but C5-A6-T6 tumor cells showed smaller values than E2 cells (Tables I-III).

In comparison to the MCF-10F cells, the tumor cells presented smaller total and absorbing nuclear areas, absorbances, and Feulgen-DNA values and larger feret ratios; in terms of nuclear perimeter, the values for the C5-A6-T6 tumor cells were also smaller, whereas those of the C5-A8T8 cells were bigger than those of the MCF-10F cells. As regards SDtd and entropy, the values presented by $\mathrm{C} 5-\mathrm{A} 8$ T8 tumor cells were smaller than those of the MCF-10F cells, whereas those presented by the C5-A6-T6 did not differ.

Fig. 1 and 2 show the nuclear phenotypes and the distribution of Feulgen-DNA amounts, respectively, in MCF$10 \mathrm{~F}$ cells treated with $\mathrm{E} 2$ and selected for invasivity and tumorigenesis (C5, C5-A6-T6, and C5-A8-T8). In all the E2transformed cell lines the decrease in Feulgen-DNA amounts is evident; in comparison to the highly invasive C5 cells, the tumor C5-A8-T8 cell line exhibited a large variability in the distribution of their Feulgen-DNA values. 
Table III. Statistical comparison of the image analysis parameters of Feulgen-stained E-2-transformed MCF-10F cells.

\begin{tabular}{|c|c|c|c|c|}
\hline Parameters & Comparisons & Test & $\mathrm{P}$ & Decision \\
\hline \multirow[t]{3}{*}{ Nuclear area } & $\begin{array}{l}\text { MCF-10F vs. E2, E2 vs. C5, C5-A6-T6 vs. C5-A8-T8, } \\
\text { E2 vs. C5-A6-T6 }\end{array}$ & Mann-Whitney & $<0.010$ & SS \\
\hline & C5 vs. C5-A6-T6 & & 0.022 & $\mathrm{~S}$ \\
\hline & E2 vs. C5-A8-T8 & & 1.000 & NS \\
\hline \multirow[t]{3}{*}{ Absorbing area } & $\begin{array}{l}\text { MCF-10F vs. E2, E2 vs. C5, C5-A6-T6 vs. C5-A8-T8, } \\
\text { E2 vs. C5-A6-T6 }\end{array}$ & Mann-Whitney & $<0.010$ & SS \\
\hline & C5 vs. C5-A6-T6 & & 0.028 & $\mathrm{~S}$ \\
\hline & E2 vs. C5-A8-T8 & & 0.740 & NS \\
\hline Nuclear perimeter & $\begin{array}{l}\text { MCF-10F vs. E2, E2 vs. C5, C5-A6-T6 vs. C5-A8-T8, } \\
\text { MCF-10F vs. C5-A6-T6, MCF-10F vs. C5-A8-T8, } \\
\text { C5 vs. C5-A6-T6, E2 vs. C5-A6-T6, E2 vs. C5-A8-T8 }\end{array}$ & Mann-Whitney & $<0.010$ & SS \\
\hline \multirow[t]{3}{*}{ Feret ratio } & MCF-10F vs. E2 & ANOVA & 0.385 & NS \\
\hline & E2 vs. C5, C5 vs. C5-A6-T6 & & $<0.010$ & SS \\
\hline & C5-A6-T6 vs. C5-A8-T8 & & 0.946 & NS \\
\hline Absorbances (OD) & $\begin{array}{l}\text { MCF-10F vs. E2, E2 vs. C5, C5-A6-T6 vs. C5-A8-T8, } \\
\text { C5 vs. C5-A6-T6 }\end{array}$ & ANOVA & 0.000 & SS \\
\hline \multirow[t]{2}{*}{ IOD } & $\begin{array}{l}\text { MCF-10F vs. E2, E2 vs. C5, C5-A6-T6 vs. C5-A8-T8, } \\
\text { C5 vs. C5-A8-T8, E2 vs. C5-A6-T6, E2 vs. C5-A8-T8 }\end{array}$ & Mann-Whitney & $<0.010$ & SS \\
\hline & C5 vs. C5-A6-T6 & & 0.846 & NS \\
\hline \multirow[t]{4}{*}{ SDtd } & $\begin{array}{l}\text { MCF-10F vs. E2, E-2 vs. C5, C5-A6-T6 vs. C5-A8-T8, } \\
\text { MCF-10F vs. C5-A8-T8, C5 vs. C5-A8-T8 }\end{array}$ & ANOVA & 0.000 & SS \\
\hline & MCF-10F vs. C5 & & 0.653 & NS \\
\hline & MCF-10F vs. C5-A6-T6 & & 0.753 & NS \\
\hline & C5 vs. C5-A6-T6 & & 0.583 & NS \\
\hline \multirow[t]{4}{*}{ Entropy } & $\begin{array}{l}\text { MCF-10F vs. E2, E2 vs. C5, C5-A6-T6 vs. C5-A8-T8, } \\
\text { MCF-10F vs. C5-A8-T8, C5 vs. C5-A8-T8 }\end{array}$ & ANOVA & 0.000 & SS \\
\hline & MCF-10 F vs. C5 & & 0.315 & NS \\
\hline & MCF-10F vs. C5-A6-T6 & & 0.102 & NS \\
\hline & C5 vs. C5-A6-T6 & & 0.554 & NS \\
\hline
\end{tabular}

n=200; E2, MCF-10F cells treated with 17-3-estradiol; C5, cells expanded from E2; C5-A6-T6 and C5-A8-T8, tumor cells; SDtd, standard deviation of total densitometric values per nucleus. NS, not significant; S, significant; SS, highly significant.

\section{Discussion}

Decrease in the DNA content and nuclear sizes of the MCF10F cells with the $\mathrm{E} 2$ treatment, as detected with quantification of the Feulgen-DNA responses and confirming previous image analysis data (6), is accented with selection of the highly invasive tumorigenesis potential in these cells. Comparative genomic hybridization in E2-transformed MCF-10F cells has revealed loss of the 9p11-13 locus in E2 cells and of the 9p11-13 and 4p loci in C5 cells (4). In addition, it is known that estrogen compromises the DNA repair system and induces aneuploidy through chromosomal instability and centromere amplification in other cell types (22-24). All these facts may play a part in the diminution of the Feulgen-DNA values and nuclear sizes as found by image analysis in E2 and C5 cells.

In the tumor-derived C5-A6-T6 and C5-A8-T8 cells the Feulgen-DNA values under statistical terms remained constant or were slightly increased in comparison to the selected invasive tumorigenic cells (C5), depending on which tumor had generated them. The tumor-derived cell lines studied herein also differed from each other as regards other image analysis parameters, which gives information on nuclear sizes and contours (nuclear areas and perimeters), and chromatin packing states (absorbances, SDtd and entropy).

According to Russo and co-workers (4), both C5-A6-T6 and C5-A8-T8 cell lines exhibit loss of chromosome 4 , 


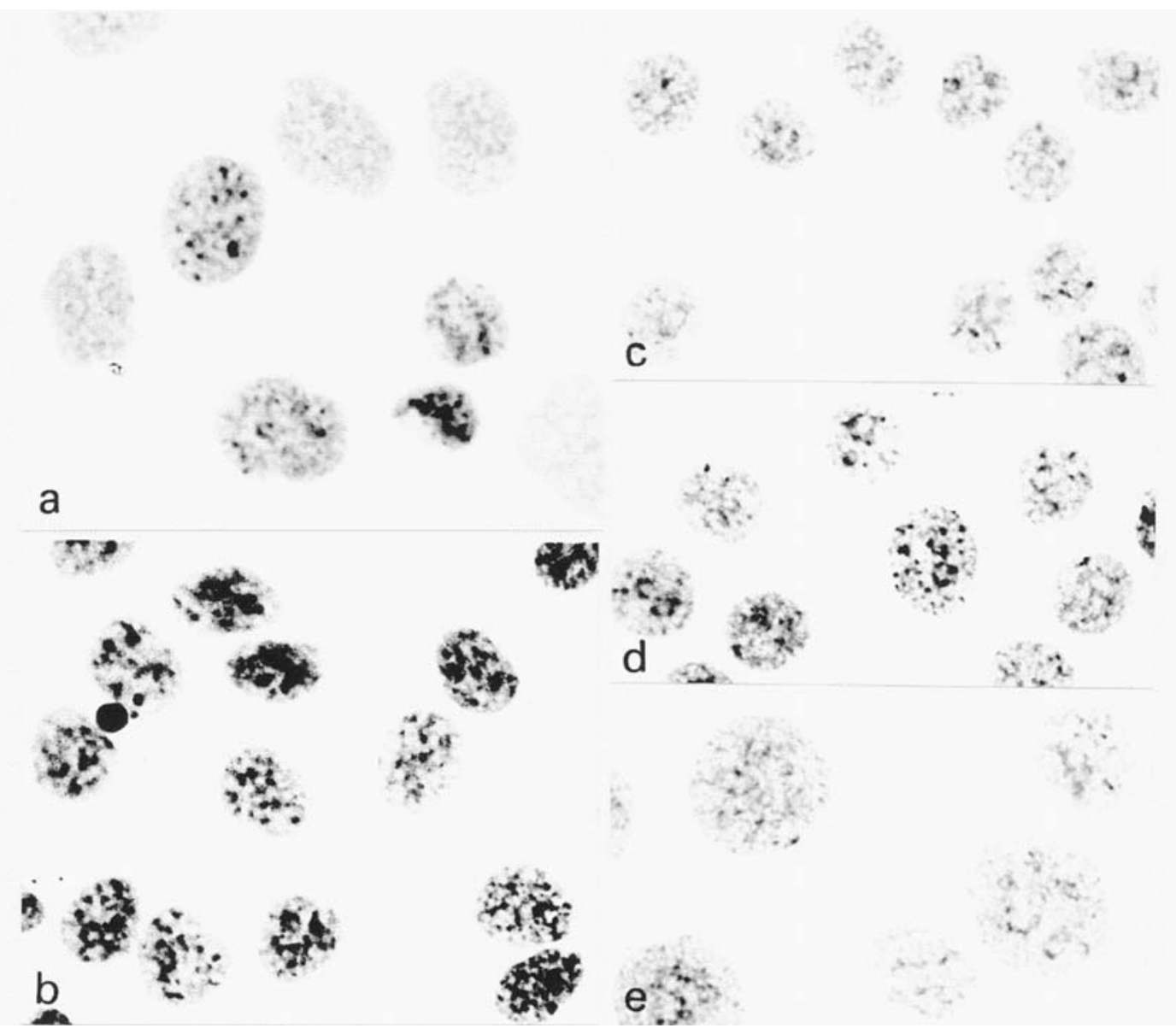

Figure 1. Feulgen-stained nuclei of nontransformed MCF-10F cells (a) and of E2-transformed (b), highly invasive C5 (c) and tumor C5-A6-T6 (d) and C5-A8-T8 cell lines.

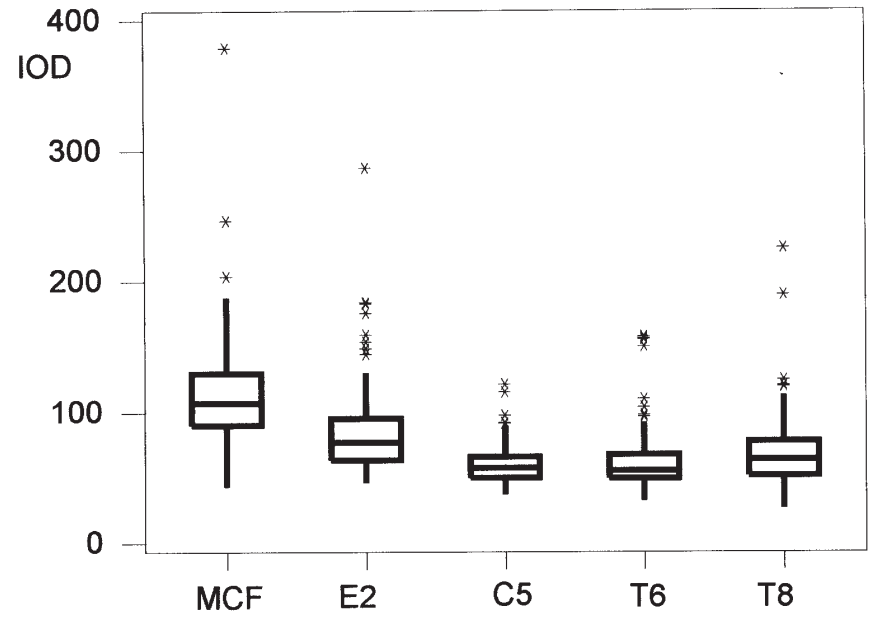

Figure 2. Tukey's box plots showing the distribution of the Feulgen-DNA content of nontransformed MCF-10F cells (MCF) and of E2-transformed (E2), highly invasive C5 and tumor C5-A6-T6 (T6) and C5-A8-T8 (T8) cell lines, $n=200$.

identical deletions and genomic gains in other chromosomes, as well as the same histopathological and immunocytochemical profile for cytokeratins, E-cadherin, vimentin, and absence of estrogen receptor $\alpha$ and of progesterone receptors. Even so, C5-A8-T8 is the most rapidly growing tumor amongst several other tumors induced in SCID mice by the C5 cells. Similar results have been reported for highly aggressive benzo[a]pyrene-transformed MCF-10F cells obtained after transfection with the c-Ha-ras oncogene (25). In this case, the Feulgen-DNA content of the MCF-10F cells, which significantly decreases with cell transformation by benzo[a]pyrene (7), increases in the benzo[a]pyrenetransformed cells additionally transfected with the c-Ha-ras oncogene, a situation assumed to be induced by a high variability in DNA content inclusively resulting from polyploidy or near-polyploidy (25). The apparent increase in Feulgen-DNA values in the C5-A8-T8 cells compared to C5 cells may thus result from a similar heterogeneity in the cellular population, which is supported by the larger variability in the distribution of the IOD values in the box plot of the former (Fig. 2).

The morphometric changes regarding the total nuclear areas, the Feulgen-DNA absorbing areas, and the nuclear perimeters are generally in agreement with the abovementioned changes in Feulgen-DNA amounts. Increased perimeters in C5, C5-A6-T6 and C5-A8-T8 cell nuclei compared to values for $\mathrm{E} 2$ cells, reflect irregularity in nuclear contours with the tumorigenesis progress. The irregularity in 
nuclear contours is especially variable in the tumor cell lines as revealed by the high standard deviations of their nuclear perimeters. The changes in nuclear feret ratio, although not discriminating the tumor cell lines from each other, indicate a trend to spheroidal rather than to ellipsoidal shapes for the nuclear images with the tumorigenesis progress, since the ratio of minimal feret/maximal feret increased.

The significant changes in SDtd, entropy and absorbances in the Feulgen-stained E2-transformed MCF-10F cell preparations are indicative of chromatin structural remodeling with the tumorigenesis process. In E2 cells, the extremely high SDtd and entropy values and an increased standard deviation for the Feulgen-DNA absorbances reflect an increase in variability for the degree of chromatin packing states $(1,19,22)$. The increase in chromatin condensation in certain sectorial nuclear domains concomitant with a decrease in condensation in less packed zones (contrast enhancement) may be involved with the control of expression efficiency in chromatin domains under relaxation $(6,7)$. With selection of the invasive potential of these cells and progression of their invasive to the tumorigenic states, the contrast between condensed and noncondensed chromatin packing states was reduced, becoming even smaller than that in control nontransformed MCF-10F cells. Considering these findings in association with a progressive decrease in Feulgen-DNA absorbances and diminution in the standard deviation for this parameter in the tumor cell lines, it is assumed that a more homogeneous packing state distribution is occurring for the chromatin of these cells, with a certain unravelling of its condensed chromatin. Epigenetic mechanisms involving DNA methylation and/or the histone code, which are known to change the chromatin packing states (26-31) are possibly playing a part in these results. Global genome hypomethylation, regional hypo- and hypermethylation and altered histone modifications have been described as epigenetic dysregulation in cancer cells (31). The chromatin texture evaluated by image analysis has been found to differ in H69 lung carcinoma drugsensitive and drug-resistant cells under treatment with the histone deacetylase inhibitor trichostatin A (27). Prominent epigenetic alterations have also been associated with increased malignant properties in MDA-MB-231 and MCF-7 human breast cancer cells (31). Additional studies on DNA methylation, histone methylation/acetylation and non-histone protein associations would contribute to a better interpretation of the chromatin textural properties and presumed functions involved in these cells.

\section{Acknowledgements}

This investigation was supported by grants from FAPESP/ Brazil (2006/00066-8), CNPq/Brazil, and the U.S. Army Medical and Research Material Command (grants: DAMD1700-1-0247 and DAMD17-031-0229).

\section{References}

1. Fernandez SV, Russo IH, Lareef MH, Balsara B and Russo J: Comparative genomic hybridization of human breast epithelial cells transformed by estrogen and its metabolites. Int J Oncol 26: 691-695, 2005.

2. Russo J, Lareef MH, Tahin Q, Hu YF, Slater C, Ao X and Russo I: 17-beta-estradiol is carcinogenic in human breast epithelial cells. J Steroid Biochem Mol Biol 80: 149-162, 2002.
3. Russo J, Tahin Q, Lareef MH, Hu YF and Russo I: Neoplastic transformation of human breast epithelial cells by estrogens and chemical carcinogens. Environ Mol Mutag 39: 254-263, 2002.

4. Russo J, Fernandez SV, Russo PA, Fernbaugh R, Sheriff FS, Lareef MH, Garber J and Russo IH: 17-beta-estradiol induces transformation and tumorigenesis in human breast epithelial cells. FASEB J 20: 1622-1634, 2006.

5. Marsit CJ, Okpukpara C, Danau H and Kelsey KT: Epigenetic silencing of the PRSS3 putative tumor suppressor gene in nonsmall cell lung cancer. Mol Carcinog 44: 146-150, 2005.

6. Mello MLS, Vidal BC, Russo IH, Lareef MH and Russo J: DNA content and chromatin texture of human breast epithelial cells transformed with 17-ß-estradiol and the estrogen antagonist ICI182,780 as assessed by image analysis. Mutat Res Fund Mol Mech Mutag 617: 1-7, 2007.

7. Vidal BC, Russo J and Mello MLS: DNA content and chromatin texture of benzo[a]pyrene-transformed human breast epithelial cells as assessed by image analysis. Exp Cell Res 244: 77-82, 1998.

8. Lareef MH, Garber J, Russo PA, Russo IH, Heulings R and Russo J: The estrogen antagonist ICI-182-780 does not inhibit the transformation phenotypes induced by 17-beta-estradiol and 4-OH estradiol in human breast epithelial cells. Int J Oncol 26: 423-429, 2005.

9. Yokota T, Matsumoto S, Yoshimoto M, Kasumi F, Akiyama F, Sakamoto G, Nakamura Y and Emi M: Mapping of a breast cancer tumor suppressor gene locus to a 4-cM interval on chromosome 18q21. Jpn J Cancer Res 88: 959-964, 1997.

10. Forozan F, Veldman R, Ammerman CA, Parsa NZ, Kallioniemi A, Kallioniemi OP and Ethier SP: Molecular cytogenetic analysis of 11 new breast cancer cell lines. Br J Cancer 81: 1328-1334, 1999.

11. Richard F, Pacyna-Gengelbach M, Schluns K, Fleige B, Winzer KJ, Szymas J, Dietel M, Petersen I and Schwendel A: Patterns of chromosomal imbalances in invasive breast cancer. Int J Cancer 89: 305-310, 2000.

12. Dellas A, Torhorst J, Schultheiss E, Mihatsch MJ and Moch H: DNA sequence losses on chromosomes $11 \mathrm{p}$ and $18 \mathrm{q}$ are associated with clinical outcome in lymph node-negative ductal breast cancer. Clin Cancer Res 8: 1210-1216, 2002.

13. Weber-Mangal S, Sinn HP, Popp S, Klaes R, Emig R, Bentz M, Mansmann U, Bastert G, Bartram CR and Jauch A: Breast cancer in young women $(<$ or $=35$ years $)$ : genomic alterations detected by comparative genomic hybridization. Int J Cancer 107: 583-592, 2003

14. Jakob J, Nagase S, Gazdar A, Chien M, Morozova I, Russo JJ, Nadula SV, Murty VV, Li CM, Tycko B and Parsons R: Two somatic biallelic lesions within and near SMAD4 in a human breast cancer cell line. Genes Chromosomes Cancer 42: 372-383, 2005.

15. Forozan F, Mahlamaki EH, Monni O, Chen YD, Veldman R, Jiang Y, Gooden GC, Ethier SP, Kallioniemi A and Kallioniemi OP: Comparative genomic hybridization analysis of 38 breast cancer cell lines: a basis for interpreting complementary DNA microarray data. Cancer Res 60: 4519-4525, 2000.

16. Calaf $\mathrm{G}$ and Russo J: Transformation of human breast epithelial cells by chemical carcinogens. Carcinogenesis 14: 483-492, 1993.

17. Mello MLS, Lareef MH, Santos AB, Russo J and Vidal BC: Nucleus image properties and cell death in MCF-1F cells grown on slide substrates differing in nature and size. In Vitro Cell Dev Biol-Animal 41: 92-96, 2005.

18. Vidal BC, Moraes AS and Mello MLS: Nucleus image properties assessed by video image analysis in mouse hepatocytes under a short lysis for extended chromatin fiber formation. Cytometry Part A 69: 1106-1113, 2006.

19. Mello MLS, Vidal BC, Lareef MH, Hu YF, Yang X and Russo J: DNA content, chromatin texture and nuclear morphology in benzo[a]pyrene-transformed human breast epithelial cells after microcell-mediated transfer of chromosomes 11 and 17 . Cytometry Part A 52: 70-76, 2003.

20. Barba J, Jeany H, Fenster P and Gil J: The use of local entropy measures in edge detection for cytological image analysis. J Microsc 156: 125-134, 1988.

21. Oberholzer M, Östreicher M, Christen H and Brühlmann M: Methods in quantitative image analysis. Histochem Cell Biol 105: 333-355, 1996.

22. Roy D and Liehr JG: Estrogen, DNA damage and mutations. Mutat Res 424: 107-115, 1999. 
23. Chakravarti D, Mainlander PC, Li KM, Higginbotham S, Zhang HL, Gross ML, Meza JL, Cavalieri EL and Rogan EG: Evidence that a birst of DNA depurination in SENCAR mouse skin induces error-prone repair and forms mutations in the H-ras gene. Oncogene 20: 7945-7953, 2001.

24. Li JJ, Weroha SJ, Lingle WL, Papa D, Salisbury JL and Li SA: Estrogen mediates Aurora-A overexpression, centrosome amplification, chromosomal instability, and breast cancer in female ACI rats. Proc Nat Acad Sci USA 101: 18123-18128, 2004.

25. Mello MLS, Vidal BC and Russo J: Ha-ras oncogene effect on DNA content and chromatin supraorganization in benzo[a]pyrenetransformed human breast epithelial cells. Anal Cell Pathol 19: 73-79, 1999.

26. Grewal SIS and Moazed D: Heterochromatin and epigenetic control of gene expression. Science 301: 798-802, 2003

27. El-Khoury V, Gomez D, Liautaud-Roger F, Trussardi-Regnier A and Dufer J: Effects of the histone deacetylase inhibitor trichostatin A on nuclear texture and c-jun gene expression in drug-sensitive and drug-resistant human H69 lung carcinoma cells. Cytometry Part A 62: 109-117, 2004.
28. Gilbert N, Gilchrist S and Bickmore WA: Chromatin organization in the mammalian nucleus. Int Rev Cytol 242: 283-336, 2005.

29. Sharma D, Blum J, Yang XW, Beaulieu N, Macleod AR and Davidson NE: Release of methyl CpG binding proteins and histone deacetylase 1 from the estrogen receptor alpha (ER) promoter upon reactivation in ER-negative human breast cancer cells. Mol Endocrinol 19: 1740-1751, 2005.

30. Stancheva I: Caught in conspiracy: cooperation between DNA methylation and histone H3K9 methylation in the establishment and maintenance of heterochromatin. Biochem Cell Biol 83: 385-395, 2005.

31. Tryndiak VP, Kovalchuk O and Pogribny IB: Loss of DNA methylation and histone $\mathrm{H} 4$ lysine 20 trimethylation in human breast cancer cells is associated with aberrant expression of DNA methyltransferase 1, Suv4-20h2 histone methyltransferase and methyl-binding proteins. Cancer Biol Ther 5: 65-70, 2006. 